UDC 517.95, 519.6

$10.23947 / 2587-8999-2018-2-76-90$

\title{
About correctness of the suspension transport and sedimentation model, taking into account bottom relief changes *
}

\author{
A.I. Sukhinov**, V.V. Sidoryakina ${ }^{* * *}$ \\ Don State Technical University, Rostov-on-Don, Russia \\ Taganrog Institute after A.P. Chekhov (branch) of RSUE, Taganrog, Russia
}

This paper is devoted to the study of the spatial-three-dimensional model of sedimentation of suspended particles in the coastal zone, taking into account changes in the bottom topography. The model takes into account the following processes: advective transfer due to movement of the aquatic environment, microturbulent diffusion and gravitational sedimentation of suspended particles, as well as changes in bottom geometry caused by sedimentation of suspended particles or rise of sediment particles. A change in the bottom relief leads to the need to solve an initial-boundary value problem for an equation of parabolic type with lower derivatives in a domain whose geometry depends on the desired solution function, which leads, in general, to a non-linear formulation of the problem. The model was linearized on a time grid due to the «freezing» of the bottom relief within one time step and the subsequent recalculation of the bottom surface function based on the changed function of suspended matter concentration, as well as a possible change in the velocity vector of the aquatic environment. For the linearized problem, a quadratic functional was constructed and the energy method proved the uniqueness of the solution of the corresponding initial-boundary problem within an arbitrary time step. Based on the transformation of the quadratic functional, an a priori estimate of the solution norm in the $\mathrm{L}_{2}$ functional space was obtained depending on the integral estimates for the right side and the initial condition, and, thus, the stability of the solution of the initial problem against the change of the initial and boundary conditions and functions of the right side. The model may be of value in predicting the spread of pollution and changes in the bottom topography, both under anthropogenic impact and due to naturally occurring natural processes in the coastal zone.

Keywords: coastal systems, mathematical model, diffusion-convection problems of deposition of suspended matter, change of the bottom relief, uniqueness of the solution and stability of the initial-boundary value problem.

\footnotetext{
* The research is done on theme no. 6905.2017/БЧ within the frame of the government task of the Ministry of Education and Science of the Russian Federation in R\&D.

** E-mail: sukhinov@gmail.com.

*** E-mail: cvv9@mail.ru.
} 
Introduction. At present, the most important tasks of hydroecology is the assessment of the state of water bodies under the influence of external (especially anthropogenic) factors, the determination of optimal conditions and the intensity of their operation. Modeling the conditions of functioning of marine systems can be considered as the foundation of a scientific understanding of their nature. A wide range of related parameters characterizes the processes occurring in marine systems: dynamic, thermohaline, chemical, biological, etc. [1]-[4]. When modeling intrawater processes and reactions of ecosystems, many parameters (both continuous and discrete) are required, that define the complex environment in which the object functions. Hence, the complexity of the mathematical models describing these processes. When considering a complex of hydrodynamic processes developing in a marine body of water, when mathematical modeling of the conditions of its functioning, special attention is paid to the problems of horizontal and vertical transfer and sedimentation of suspended matter [5]-[9]. Based on the results of field experiments, the authors constructed a continuous mathematical model describing 3D processes associated with transport and gravitational sedimentation of suspensions in the aquatic environment with varying bottom topography. This model takes into account microturbulent diffusion and advective transfer of suspended matter, the effect of gravity on suspended particles, the presence of a bottom and a free surface, a change in the bottom relief [10]-[12].

The paper presents sufficient conditions for the existence and uniqueness of the solution of the corresponding initial-boundary value problem, as well as an a priori estimate of the norm of the solution, obtained depending on the integral estimates of the right-hand side, boundary conditions, and the initial condition.

\section{Simulation of lifting, transfer and sedimentation of suspended particles in shallow water}

areas. A lot of geophysical factors influence on the processes of weighing, redistribution and transport of bottom material are by, among which the effects of waves and currents are the most significant (Fig. 1).

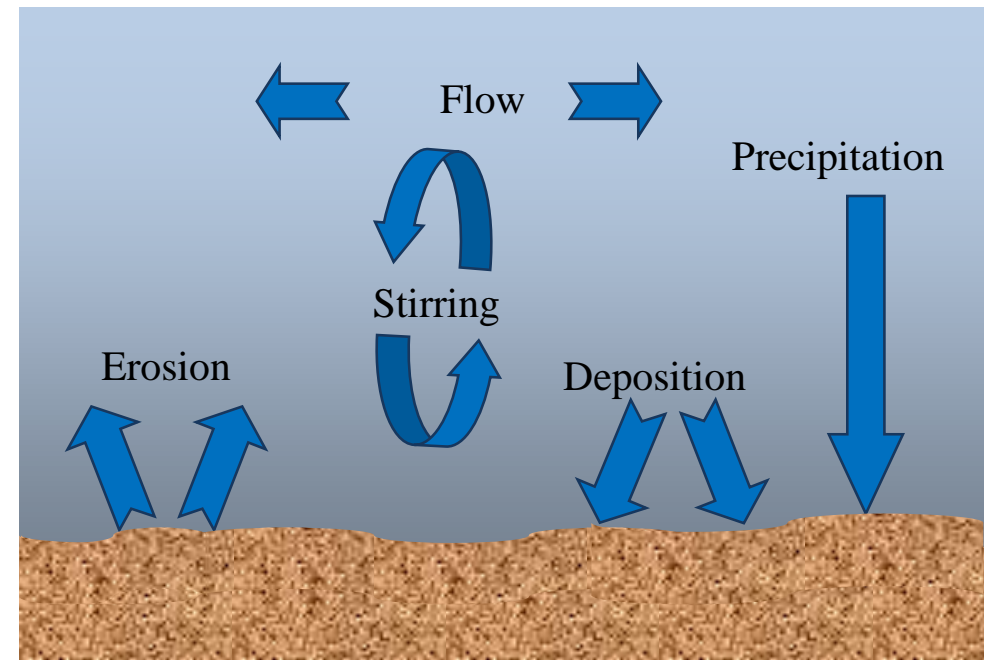

Fig. 1. Diagram of the process of lifting-deposition of bottom particles 
There are several mechanisms for the horizontal and vertical movement of suspended particles. Under the action of gravity particles suspended in the water flow down. Vertical mixing occurs in the ascending and descending directions respectively. The interaction between these two processes provides a vertical concentration profile.

Under the action of a gravitational field or centrifugal forces, the suspension of suspended particles in water occurs. The deposition rate depends on the mass, size, shape and density of the particle, the viscosity of the medium, which, in turn, depends on temperature and salinity, as well as the mode of movement of water. Organic and inorganic particles form bottom sediments, which are the main reason for changing the topography of the water body. Inorganic substances consist mainly of clay minerals (silica, alumina, montmorillonite, etc.) and non-clay minerals (quartz, mica, etc.). Organic materials mainly exist in the form of plants and bacteria.

Suspended solids have a different particle size distribution. The size and shape of the water particles are their important characteristics, allowing to draw conclusions about the processes of transfer, sorting and sedimentation. For example, spherical particles are deposited faster than particles of irregular shape, and therefore, sand particles (due to their shape and weight) are deposited rather quickly, and particles of fine clay and colloids are deposited slowly if they are not grouped (coagulated particles). Finally, quite often (during coagulation) one has to deal with the deposition of an aggregately unstable suspension, the particles of which change their structure and size during the deposition process.

For high-quality particle-size analysis, the entire possible range of sizes of water particles is divided into areas, the so-called fractions. We believe that the particle size is determined by the diameter and is expressed in millimeters. The work [13] presents the results of a comprehensive study of the features of the particle size distribution of various types of particles in the water area of the Taganrog Bay, which were obtained in the course of field experiments, in particular, using seismic methods. Particles with a range of diameters from less than $0.005 \mathrm{~mm}$ to $1-2 \mathrm{~mm}$ can be found in this reservoir. The percentage of granulometric fractions substantially depends on the specific territory of the Taganrog Bay. Thus, silty fine-grained sands with inclusions of shell detritus predominate in the eastern part of the bay; to the west, the particle size distribution changes in the direction of decreasing the size of the particles; clay and silty-clay oozes are accumulated in the center of the bay.

For example, we present the results of particle size analysis of bottom sediments obtained at one of the stations in the eastern part of the Taganrog Bay opposite Chumbur-Kosa (Table 1).

Table 1. Results of particle size analysis of bottom sediments in the eastern part of Taganrog Bay

\begin{tabular}{|c|c|c|c|c|c|c|c|c|}
\hline \multirow{2}{*}{$\begin{array}{c}\text { Interval } \\
(\mathrm{sm})\end{array}$} & \multicolumn{10}{|c|}{ Granulometric composition in \% } \\
\cline { 2 - 11 } & $\mathrm{m}$ & $\begin{array}{c}1-0,5 \\
\mathrm{~mm} .\end{array}$ & $\begin{array}{c}0,5-0,25 \\
\mathrm{~mm} .\end{array}$ & $\begin{array}{c}0,25-0,125 \\
\mathrm{~mm} .\end{array}$ & $\begin{array}{c}0,125-0,1 \\
\mathrm{~mm} .\end{array}$ & $\begin{array}{c}0,1-0,05 \\
\mathrm{~mm} .\end{array}$ & $\begin{array}{c}0,05-0,01 \\
\mathrm{~mm} .\end{array}$ & $\begin{array}{c}<0,01 \\
\mathrm{~mm} .\end{array}$ \\
\hline $0-14$ & 1,43 & 0,47 & 3,52 & 16,47 & 10,3 & 12,34 & 19,46 & 36,01 \\
\hline $14-67$ & 1,53 & 0,76 & 2,06 & 11,86 & 2,89 & 6,02 & 10,99 & 63,89 \\
\hline $67-95$ & 0,06 & 0,22 & 0,63 & 19,48 & 11,52 & 20,14 & 27,7 & 20,25 \\
\hline
\end{tabular}


The particle size distribution for each fraction is characterized by hydraulic size $w_{g}$ or the rate of sedimentation of particles in still water. Hydraulic size $w_{g}$ in the turbulent mode, one can find from the condition of equality of the force, the moving particle and the drag force of the aquatic environment:

$$
w_{g}=\sqrt{\frac{4 d_{p}\left(\rho_{p}-\rho_{0}\right) \cdot g}{3 \xi \cdot \rho_{0}}},
$$

where $d_{p}$ is the particle diameter, $g$ is the acceleration of gravity $\mathrm{g}=9,80665, \rho_{p}$ is the solid particle density, $\rho_{0}$ is the density of water, $\xi$ is the coefficient of resistance of the aqueous medium (for a spherical medium $\xi \approx 0,45$ ).

In the laminar mode (the fluid moves in layers without transverse mixing, with no velocity and pressure pulsations) for a single spherical particle, the rate of particle deposition is expressed as the Stokes formula

$$
w_{g}=\frac{g \cdot d_{p}^{2}\left(\rho_{p}-\rho_{0}\right)}{18 \eta \cdot \rho_{0}},
$$

where $\eta$ is the dynamic viscosity.

If the granulometric composition is fairly uniform and the average values of the particle diameters of the fractions can be considered constant, then the Stokes formula (2) can be used depending on the mode of water movement when obtaining estimates of sedimentation rate In the case of a significant scatter of the average values of particle diameters and heterogeneity in the granulometric composition of the soil, it is necessary to use the formula (1).

Mathematical continuous 3D model of diffusion-convection suspension and the corresponding initial boundary value problem. Let us consider a continuous mathematical model of suspended matter propagation in an aqueous medium, taking into account diffusion and convection of suspended matter, the effect of gravity on suspension, the presence of a bottom and a free surface. We will use rectangular Cartesian coordinate system $O x y z$, where is the axis $O x$ passes on undisturbed water surface and is directed towards the sea, the axis $O z$ directed vertically down. Let be $h=H+\eta$ is the total water depth, [m]; $H$ is the depth with undisturbed surface of the reservoir, $[\mathrm{m}] ; \eta$ is the elevation of the free surface relative to the geoid (sea level), [m].

Let in the closure area $\bar{G}=\left\{0 \leq x \leq L_{x}, 0 \leq y \leq L_{y}, 0 \leq z \leq H(x, y)\right\}$ there are suspended particles that are at $(x, y, z)$ and at the time $t$ have concentration $c=c(x, y, z, t),[\mathrm{mg} / 1] ; t$ is the temporary variable, [sec]. We will also use the notation $L_{z} \equiv \max _{0 \leq x \leq L_{x}, 0 \leq y \leq L_{y}} H(x, y)$.

The behavior of suspended particles will be described by the following system of equations: 


$$
\left\{\begin{array}{l}
\frac{\partial c}{\partial t}+\frac{\partial(u c)}{\partial x}+\frac{\partial(v c)}{\partial y}+\frac{\partial\left(\left(w+w_{g}\right) c\right)}{\partial z}=\mu_{h}\left(\frac{\partial^{2} c}{\partial x^{2}}+\frac{\partial^{2} c}{\partial y^{2}}\right)+\frac{\partial}{\partial z}\left(\mu_{v} \frac{\partial c}{\partial z}\right)+F, \\
\frac{\partial H}{\partial t}=-\frac{\varepsilon}{\rho} w_{g} c
\end{array}\right.
$$

where $u, v, w$ are vector components, $\vec{U}$ is the fluid velocity, $[\mathrm{m} / \mathrm{s}] ; w_{g}$ is the hydraulic particle size or sedimentation rate, $[\mathrm{m} / \mathrm{s}] ; \mu_{h}, \mu_{v}$ are coefficients of horizontal and vertical turbulent diffusion of particles, respectively, $\left[\mathrm{m}^{2} / \mathrm{s}\right] ; F$ is the power source of particles; $\varepsilon$ is the bottom porosity.

The terms on the left side (except for the time derivative) of the first equation of system (3) describe the advective transport of particles due to the inertial motion of the aquatic environment and sedimentation under the action of gravity. The terms on the right-hand side describe the diffusion of the suspension. The vertical diffusion coefficient is chosen different from the horizontal diffusion coefficient due to the fact that the effect of the difference of these coefficients is often observed in different environments and can be caused by various factors.

As an area $G$ consider parallelepiped «beveled» to the shore $A B C D A_{1} O C_{1} D_{1}$, top base $A_{1} O C_{1} D_{1}$ which lies on the free surface $(z=0)$, and the bottom base $A B C D$ is part of the bottom surface $(z=H(x, y))$. Let be $S-$ surface $\bar{G}, \vec{n}-$ external normal to the surface of the «bevelled parallelepiped». We assume a given $\overrightarrow{U^{*}}$ - fluid velocity on the side surfaces $\bar{G}$. Together with the boundary conditions of the first kind for the particle concentration function, this makes it possible to determine the flux of suspended matter both toward the coast and along the coast (Fig. 2).

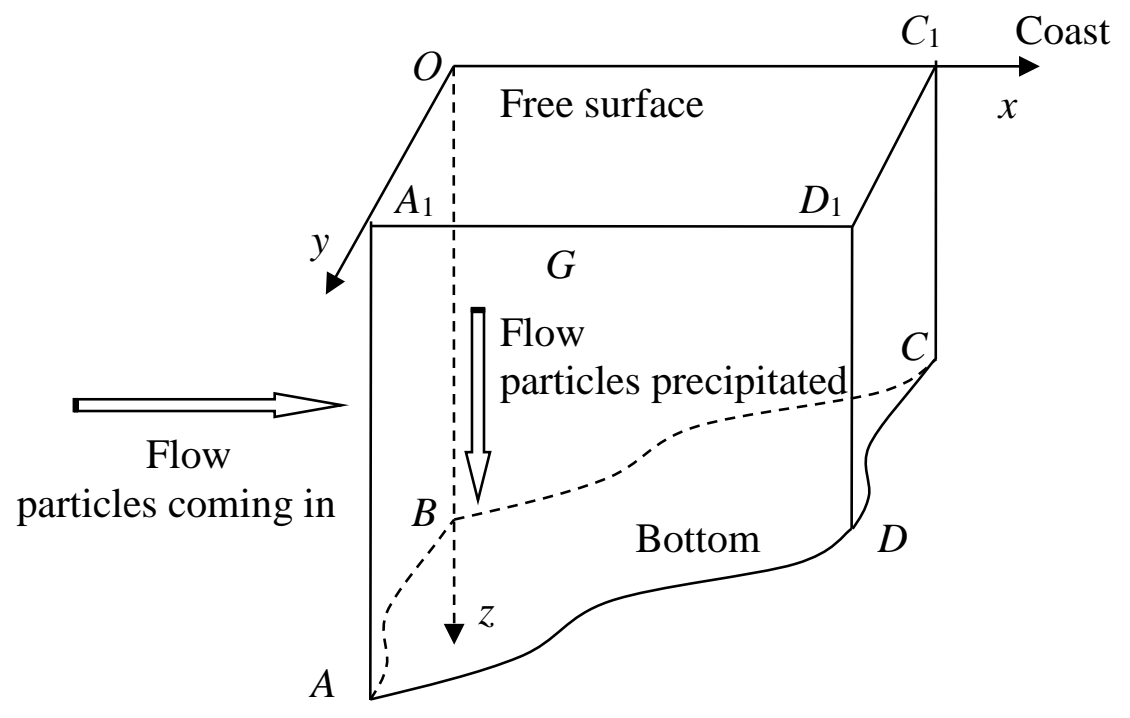

Fig. 2. Solution area for the transport of suspended matter 
Add to system (3) the initial and boundary conditions (assuming that the deposition of particles on the bottom is irreversible).

As initial conditions at time $t=0$ accept

$$
\begin{aligned}
& c(x, y, z, 0) \equiv c_{0}(x, y, z) ; \\
& H(x, y, 0)=H_{0}(x, y) .
\end{aligned}
$$

We set boundary conditions on the edges. $A B C D A O C_{1} D_{1}$ (we set streams of suspensions both towards the coast, and along the coast)

- on the edges $S_{1} \equiv A A_{1} O B\left(x=0,0 \leq y \leq L_{y}, 0 \leq z \leq L_{z}\right)$,

$$
\begin{aligned}
& S_{2} \equiv A A_{1} D_{1} D\left(y=L_{y}, 0 \leq x \leq L_{x}, 0 \leq z \leq L_{z}\right), \\
& S_{3} \equiv B O C_{1} C\left(y=0,0 \leq x \leq L_{x}, 0 \leq z \leq L_{z}\right) \\
& c=c^{*}, \text { where } c^{*}=c^{*}(x, y, z, t), t \in[0, T] ;
\end{aligned}
$$

- on the edges $S_{4} \equiv D D_{1} C_{1} C\left(x=L_{x}, 0 \leq y \leq L_{y}, 0 \leq z \leq L_{z}\right)$

$$
\begin{gathered}
S_{5} \equiv A_{1} O C_{1} D_{1} \quad\left(z=0,0 \leq x \leq L_{x}, 0 \leq y \leq L_{y}\right) \\
c=0 ;
\end{gathered}
$$

- on a surface $S_{6} \equiv A B C D\left(z=H(x, y, t), 0 \leq x \leq L_{x}, 0 \leq y \leq L_{y}\right)$

$$
\frac{\partial c}{\partial n}=-\frac{w_{g}}{\mu_{v}} c \text { or } \frac{\partial c}{\partial z}=-\frac{w_{g}}{\mu_{v}} c \text {. }
$$

The boundary condition (7) takes place with relatively small bottom slopes:

$$
\max _{S_{6}} \sqrt{\left(\frac{\partial H}{\partial x}\right)^{2}+\left(\frac{\partial H}{\partial y}\right)^{2}} \square 1 .
$$

The following condition of non degeneracy of the solution domain is set for all $(x, y, t)$ under which the initial boundary problem is posed:

$$
H(x, y, t) \geq h_{0} \equiv \text { const }>0,0 \leq t \leq T .
$$

When studying combined sediment and sediment transport models, it is possible to increase the concentration of suspended particles in the bottom layer due to the rise of sediment particles when the shear stress exceeds a certain critical value [14]-[17]. Then instead of the boundary condition (8) we will consider the boundary condition of the form

$$
\frac{\partial c}{\partial z}=\alpha c, \alpha=\text { const }>0 \text {. }
$$

\section{Linearization of the initial-boundary value problem of transport and sedimentation of} suspensions. In order to create a linearized model on a time interval $0 \leq t \leq T$ build a uniform grid $\omega_{\tau}$ in steps $\tau$, i.e. many points $\omega_{\tau}=\left\{t_{n}=n \tau, n=0,1, \ldots, N, N \tau=T\right\}$.

Functions $c^{(n)}\left(x, y, z, t_{n-1}\right)$ and $H^{(n)}\left(x, y, t_{n-1}\right)$ we define at each step of the time grid $\omega_{\tau}$. If a $n=1$, then as $c^{(1)}\left(x, y, z, t_{0}\right), H^{(1)}\left(x, y, t_{0}\right)$ it is enough to take the functions of the initial condition, that is $c^{(1)}(x, y, z, 0) \equiv c_{0}(x, y, z), H^{(1)}\left(x, y, t_{0}\right) \equiv H_{0}(x, y) \quad$ respectively. If $n=2, \ldots, N$, then functions 
$c^{(n)}\left(x, y, z, t_{n-1}\right)=c^{(n-1)}\left(x, y, z, t_{n-1}\right)$ assumed to be known, since problem (3) - (8) for the previous time interval is assumed to be solved $\mathrm{t}_{n-2}<t \leq \mathrm{t}_{n-1}$.

System (3) in the gap $\mathrm{t}_{n-1}<t \leq \mathrm{t}_{n}$ we write in the form:

$$
\left\{\begin{array}{l}
\frac{\partial c^{(n)}}{\partial t}+\frac{\partial\left(u c^{(n)}\right)}{\partial x}+\frac{\partial\left(v c^{(n)}\right)}{\partial y}+\frac{\partial\left(\left(w+w_{g}\right) c^{(n)}\right)}{\partial z}=\mu_{h}\left(\frac{\partial^{2} c^{(n)}}{\partial x^{2}}+\frac{\partial^{2} c^{(n)}}{\partial y^{2}}\right)+\frac{\partial}{\partial z}\left(\mu_{v} \frac{\partial c^{(n)}}{\partial z}\right)+F \\
\frac{\partial H^{(n)}}{\partial t}=-\frac{\varepsilon}{\rho} w_{g} c^{(n)}
\end{array}\right.
$$

and supplement it with the initial conditions:

$$
\begin{aligned}
& c^{(1)}\left(x, y, z, t_{0}\right)=c_{0}(x, y, z), \\
& c^{(n)}\left(x, y, z, t_{n-1}\right)=c^{(n-1)}\left(x, y, z, t_{n-1}\right), n=2, \ldots, N . \\
& H^{(1)}\left(x, y, t_{0}\right)=H_{0}(x, y), \\
& H^{(n)}\left(x, y, t_{n-1}\right)=H^{(n-1)}\left(x, y, t_{n-1}\right), n=2, \ldots, N .
\end{aligned}
$$

The boundary conditions (6) - (8) are assumed to be satisfied for all time intervals $\mathrm{t}_{n-1}<t \leq \mathrm{t}_{n}, n=1,2, \ldots, N$.

Defining the function $c^{(n)}\left(x, y, z, t_{n-1}\right)=c^{(n-1)}\left(x, y, z, t_{n-1}\right)$ in the time interval $\mathrm{t}_{n-1}<t \leq \mathrm{t}_{n}$, can find function $H^{(n)}\left(x, y, t_{n-1}\right)$. To this end, we integrate both sides of the second equation of system (11) over the variable $\mathrm{t}, \mathrm{t}_{n-1}<t \leq \mathrm{t}_{n}$. Will get

$$
\int_{t_{n-1}}^{t_{n}} \frac{\partial H^{(n)}}{\partial t} d t=-\frac{\varepsilon}{\rho} w_{g} \int_{t_{n-1}}^{t_{n}} c^{(n)} d t
$$

From equality (14) it is not difficult to get

$$
H^{(n)}=H^{(n-1)}-\frac{\varepsilon}{\rho} w_{g} \sum_{n=t_{n-1}}^{N} \int_{t_{n-1}}^{t_{n}} c^{(n)} d t
$$

We introduce at each time step $\mathrm{t}_{n-1}<t \leq \mathrm{t}_{n}, n=1,2, \ldots, N$ region $G_{n-1}=\left\{0<x<L_{x}, 0<y<L_{y}, 0<z<H^{n-1}\left(x, y, t_{n-1}\right)\right\}$.

We have a chain of linear initial-boundary value problems for each time layer, where for the interval $\mathrm{t}_{n-1}<t \leq \mathrm{t}_{n}, n=1,2, \ldots, N$ view system is considered

$$
\left\{\begin{array}{l}
\frac{\partial c^{(n)}}{\partial t}+\frac{\partial\left(u c^{(n)}\right)}{\partial x}+\frac{\partial\left(v c^{(n)}\right)}{\partial y}+\frac{\partial\left(\left(w+w_{g}\right) c^{(n)}\right)}{\partial z}=\mu_{h}\left(\frac{\partial^{2} c^{(n)}}{\partial x^{2}}+\frac{\partial^{2} c^{(n)}}{\partial y^{2}}\right)+\frac{\partial}{\partial z}\left(\mu_{v} \frac{\partial c^{(n)}}{\partial z}\right)+F \\
(x, y, z) \in G_{n-1}, \\
G_{n-1}=\left\{0<x<L_{x}, 0<y<L_{y}, 0<z<H^{n-1}\left(x, y, t_{n-1}\right)\right\} \\
H^{(n)}=H^{(n-1)}-\frac{\varepsilon}{\rho} w_{g} \sum_{n=1}^{N} \int_{t_{n-1}}^{t_{n}} c^{(n)} d t, n=1,2, \ldots, N
\end{array}\right.
$$

with initial conditions: 


$$
\begin{aligned}
& c^{(n)}\left(x, y, z, t_{n-1}\right)=c^{(n-1)}\left(x, y, z, t_{n-1}\right), \\
& H^{(n)}\left(x, y, t_{n-1}\right)=H^{(n-1)}\left(x, y, t_{n-1}\right)
\end{aligned}
$$

Note that at each time step, the boundary surfaces will change (except the face $S_{5}$ ). Considering the time span $t_{n-1} \leq t \leq t_{n}$, we carry out the task of boundary conditions on the edges of the region $G_{n-1}$ :

- on the edges $S_{1, n-1}\left(x=0,0 \leq y \leq L_{y}, 0 \leq z \leq H^{(n-1)}\left(0, y, t_{n-1}\right)\right)$,

$$
\begin{aligned}
& S_{2, n-1}\left(y=L_{y}, 0 \leq x \leq L_{x}, 0 \leq z \leq H^{(n-1)}\left(x, L_{y}, t_{n-1}\right)\right) \\
& S_{3, n-1}\left(y=0,0 \leq x \leq L_{x}, 0 \leq z \leq H^{(n-1)}\left(x, 0, t_{n-1}\right)\right) \\
& c^{(n)}=c^{*}, \text { where } c^{*}=c^{*}(x, y, z, t), t \in\left[t_{n-1}, t_{n}\right] ;
\end{aligned}
$$

- on the edges $S_{4, n-1}\left(x=L_{x}, 0 \leq y \leq L_{y}, 0 \leq z \leq H^{(n-1)}\left(L_{x}, y, t_{n-1}\right)\right)$

$$
\begin{array}{r}
S_{5, n-1}\left(z=0,0 \leq x \leq L_{x}, 0 \leq y \leq L_{y}\right) \equiv A_{1} O C_{1} D_{1} \\
c^{(n)}=0 ;
\end{array}
$$

- on a surface $S_{6, n-1}\left(z=H^{(n-1)}\left(x, y, t_{n-1}\right), 0 \leq x \leq L_{x}, 0 \leq y \leq L_{y}\right)$

$$
\frac{\partial c^{(n)}}{\partial n}=-\frac{w_{g}}{\mu_{v}} c^{(n)} \text { or } \frac{\partial c^{(n)}}{\partial z}=-\frac{w_{g}}{\mu_{v}} c^{(n)} .
$$

The boundary condition (10) will be replaced by the following

$$
\frac{\partial c^{(n)}}{\partial z}=\alpha c^{(n)}, \alpha=\text { const }>0 .
$$

Thus, it is assumed that the bottom relief within a given time step when calculating the distribution of concentrations of suspended matter does not change and is taken from the previous time layer. Initially at this time step $\mathrm{t}_{n-1}<t \leq \mathrm{t}_{n}, n=1,2, \ldots, N$ the initial boundary value problem is solved for the convection-diffusion equation (16) with a fixed bottom relief function $H^{(n-1)}$, and then an update (recalculation) of the relief function is performed $H^{(n)}$ in accordance with equality (17). The determination of the conditions of existence, uniqueness and continuous dependence of the solution on the input data of the problem is carried out on a fixed time layer in these assumptions and subject to condition (9).

We will not investigate in this paper the existence of solutions of the initial boundary value problems (16)-(22) and (16)-(21), (23). Questions of the existence of solutions of initial-boundary value problems for equations of parabolic type with lower derivatives (diffusion-convection equations) are considered, for example, in monographs [18]-[21].

\section{transport.}

Results of the study of the solution of the initial-boundary problem of suspension

Theorem 1. Let given a system of equations 


$$
\left\{\begin{array}{l}
\frac{\partial c^{(n)}}{\partial t}+\frac{\partial\left(u c^{(n)}\right)}{\partial x}+\frac{\partial\left(v c^{(n)}\right)}{\partial y}+\frac{\partial\left(\left(w+w_{g}\right) c^{(n)}\right)}{\partial z}=\mu_{h}\left(\frac{\partial^{2} c^{(n)}}{\partial x^{2}}+\frac{\partial^{2} c^{(n)}}{\partial y^{2}}\right)+\frac{\partial}{\partial z}\left(\mu_{v} \frac{\partial c^{(n)}}{\partial z}\right)+F, \\
(x, y, z) \in G_{n-1}, \\
G_{n-1}=\left\{0<x<L_{x}, 0<y<L_{y}, 0<z<H^{n-1}\left(x, y, t_{n-1}\right)\right\}, \\
H^{(n)}=H^{(n-1)}-\frac{\varepsilon}{\rho} w_{g} \sum_{n=I_{n-1}}^{t_{n}} c^{(n)} d t, n=1,2, \ldots, N
\end{array}\right.
$$

in a simply connected domain $\Omega_{n-1}=G_{n-1} \times\left(t_{n-1}<t<t_{n}\right), G_{n-1}=\left(0<x<L_{x}, 0<y<L_{y}, 0<z<H^{(n-1)}\left(x, y, t_{n-1}\right)\right)$, with a fairly smooth boundary defined by the smoothness of the function $z=H^{(n-1)}(x, y), 0 \leq x \leq L_{x}, 0 \leq y \leq L_{y}$ with initial and boundary conditions (18)-(22). Let solution functions $c^{(n)}\left(x, y, z, t_{n-1}\right)$, water velocity vector $\left\|u, v, w+w_{g}\right\|^{T}$, initial condition $c^{(n-1)}\left(x, y, z, t_{n-1}\right)$, right side $F(x, y, z, t)$, boundary condition $c^{*}(x, y, z, t)$, coefficient of vertical turbulent exchange $\mu_{v}=\mu_{v}(z),(x, y, z) \in G_{n-1}$ satisfy the following smoothness conditions: $\quad c^{(n)}\left(x, y, z, t_{n-1}\right) \in C^{2}\left(\Omega_{n-1}\right) \cap C\left(\bar{\Omega}_{n-1}\right), \quad \operatorname{gradc}^{(n)} \in C\left(\bar{\Omega}_{n-1}\right),\left\|u, v, w+w_{g}\right\|^{T} \in C^{1}\left(\Omega_{n-1}\right) \cap C\left(\bar{\Omega}_{n-1}\right)$, $c^{(n-1)}\left(x, y, z, t_{n-1}\right) \in C\left(\bar{G}_{n-1}\right), \quad F(x, y, z, t) \in C\left(\Omega_{n-1}\right), \quad \mu_{v}(x, y, z) \in C^{1}\left(G_{n-1}\right) \cap C\left(\bar{G}_{n-1}\right), \quad c^{*}(x, y, z, t) \in C\left(S_{n-1}\right) \times\left[t_{n-1} \leq t \leq t\right]$, $S_{n-1}=\bar{G}_{n-1} \backslash G_{n-1}, \quad \frac{\partial c^{*}}{\partial n} \in C\left(\left(0 \leq x \leq L_{x}, 0 \leq y \leq L_{y}, z=H^{(n-1)}(x, y)\right) \times\left[t_{n-1} \leq t \leq t_{n}\right]\right), \quad$ as well as the conditions of consistency of the boundary and initial conditions, $c^{*}(x, y, z, 0)=c_{0}(x, y, z)$, $(x, y, z) \in S_{n-1}\left(\left(0<x<L_{x}, 0<y<L_{y}, z=H^{(n-1)}(x, y)\right), \quad \frac{\partial c_{0}}{\partial z}=-\frac{\mu_{v}}{w_{g}} c^{*}, \quad\left(0<x<L_{x}, 0<y<L_{y}, z=H^{(n-1)}(x, y)\right), \quad\right.$ then the solution to this problem exists and is unique.

The idea of the proof of the theorem is as follows. It is assumed the existence of two solutions to the specified problem with $t_{n-1} \leq t \leq t_{n}: c_{1}=c_{1}(x, y, z, t), c_{2}=c_{2}(x, y, z, t),(x, y, z) \in \bar{G}_{n-1}$. Introduces the function $\tilde{c}=c_{1}-c_{2}, \tilde{\mathrm{c}} \neq 0, t_{n-1} \leq t \leq t_{n},(x, y, z) \in \bar{G}_{n-1}$.

For $\tilde{c}(x, y, z, t), t_{n-1} \leq t \leq t_{n},(x, y, z) \in \bar{G}_{n-1}$ an initial boundary value problem is considered, for which equation (14) after simple transformations takes the form:

$$
\frac{\partial \tilde{c}}{\partial t}+\frac{\partial(u \tilde{c})}{\partial x}+\frac{\partial(v \tilde{c})}{\partial y}+\frac{\partial\left(\left(w+w_{g}\right) \tilde{c}\right)}{\partial z}=\mu_{h}\left(\frac{\partial^{2} \tilde{c}}{\partial x^{2}}+\frac{\partial^{2} \tilde{c}}{\partial y^{2}}\right)+\frac{\partial}{\partial z}\left(\mu_{v} \frac{\partial \tilde{c}}{\partial z}\right)
$$

Investigating the resulting task and demanding the fulfillment of inequality

$$
\alpha \leq \frac{w_{g}}{2 \mu_{v}},(x, y, z) \in S_{6, n-1}, t_{n-1}<t \leq t_{n},
$$

we get $\tilde{c}(x, y, \mathrm{z}, t) \equiv 0,(x, y, z) \in G_{n-1}, t_{n-1}<t \leq t_{n}$, which means the uniqueness of the solution.

By similar reasoning, it is proved that for all layers of the time grid $\omega_{\tau}$.

Comment. If the boundary condition (20) is replaced by the boundary condition (21), inequality (40) should be added as a sufficient condition for the fulfillment of the previous theorem.

Further, we will assume that

$$
\begin{gathered}
c^{*} \geq c_{0}^{*} \equiv \text { const }>0, \\
0 \leq x \leq L_{x}, 0 \leq y \leq L_{y}, 0<z<H^{(n)}\left(x, y, t_{n-1}\right), t_{n-1} \leq t \leq t_{n} .
\end{gathered}
$$


We introduce the notation: the union of all parts of the lateral cylindrical surface - the boundaries of the region $G_{n-1}$ denote as $S_{c, n-1}$, and the lower base of the area $G_{n-1}-S_{b, n-1}$.

Theorem 2. Let given a system of equations

$$
\left\{\begin{array}{l}
\frac{\partial c^{(n)}}{\partial t}+\frac{\partial\left(u c^{(n)}\right)}{\partial x}+\frac{\partial\left(v c^{(n)}\right)}{\partial y}+\frac{\partial\left(\left(w+w_{g}\right) c^{(n)}\right)}{\partial z}=\mu_{h}\left(\frac{\partial^{2} c^{(n)}}{\partial x^{2}}+\frac{\partial^{2} c^{(n)}}{\partial y^{2}}\right)+\frac{\partial}{\partial z}\left(\mu_{v} \frac{\partial c^{(n)}}{\partial z}\right)+F, \\
(x, y, z) \in G_{n-1}, \\
G_{n-1}=\left\{0<x<L_{x}, 0<y<L_{y}, 0<z<H^{n-1}\left(x, y, t_{n-1}\right)\right\}, \\
H^{(n)}=H^{(n-1)}-\frac{\varepsilon}{\rho} w_{g} \sum_{n=1}^{N} \int_{t_{n-1}}^{t_{n}} c^{(n)} d t, n=1,2, \ldots, N
\end{array}\right.
$$

and function $c^{(n)}\left(x, y, z, t_{n-1}\right)$ class $C^{2}\left(\Omega_{n-1}\right) \cap C\left(\bar{\Omega}_{n-1}\right), \operatorname{grad} c^{(n)} \in C\left(\bar{\Omega}_{n-1}\right),\left\|u, v, w+w_{g}\right\|^{T} \in C^{1}\left(\Omega_{n-1}\right) \cap C\left(\bar{\Omega}_{n-1}\right)$, is a solution to the number equation $n$ said system in the area $\Omega_{n-1}=G_{n-1} \times\left(t_{n-1}<t<t_{n}\right)$, $G_{n-1}=\left(0<x<L_{x}, 0<y<L_{y}, 0<z<H^{(n-1)}\left(x, y, t_{n-1}\right)\right)$ with initial and boundary conditions (18)-(22). Let the initial condition function $c^{(n-1)}\left(x, y, z, t_{n-1}\right)$, right side $F(x, y, z, t)$, boundary condition $c^{*}(x, y, z, t)$, coefficient of vertical turbulent exchange $\mu_{v}=\mu_{v}(z),(x, y, z) \in G_{n-1}$ satisfy the following smoothness conditions: $c^{(n-1)}\left(x, y, z, t_{n-1}\right) \in C\left(\bar{G}_{n-1}\right), \quad \quad F(x, y, z, t) \in C\left(\Omega_{n-1}\right), \quad \quad \mu_{v}(x, y, z) \in C^{1}\left(G_{n-1}\right) \cap C\left(\bar{G}_{n-1}\right)$, $c^{*}(x, y, z, t) \in C\left(S_{n-1}\right) \times\left[t_{n-1} \leq t \leq t_{n}\right], S_{n-1}=\bar{G}_{n-1} \backslash G_{n-1}, \frac{\partial c^{*}}{\partial n} \in C\left(\left(0 \leq x \leq L_{x}, 0 \leq y \leq L_{y}, z=H^{(n-1)}(x, y)\right) \times\left[t_{n-1} \leq t \leq t_{n}\right]\right)$, as well as the conditions of consistency of the boundary and initial conditions, $c^{*}(x, y, z, 0)=c_{0}(x, y, z)$, $(x, y, z) \in S_{n-1} \backslash\left(0<x<L_{x}, 0<y<L_{y}, z=H^{(n-1)}(x, y)\right), \frac{\partial c_{0}}{\partial z}=-\frac{\mu_{v}}{w_{g}} c^{*}, \quad\left(0<x<L_{x}, 0<y<L_{y}, z=H^{(n-1)}(x, y)\right)$, Then, under the conditions (26), the following estimates take place:

$$
\begin{aligned}
& \iiint_{G_{n-1}}\left(c^{(n)}\right)^{2} d G_{n-1} \leq \iiint_{G_{n-1}} c_{0}^{2} d G_{n-1}+M_{4, n-1} \int_{t_{n-1}}^{t_{n}}\left(\iint_{S_{c, n-1}}\left(c^{*}\right)^{2} d S_{n-1}\right) d t+ \\
& +2 M_{2, n-1} M_{3, n-1} \int_{t_{n-1}}^{t_{n}}\left(\iint_{S_{c, n-1}}\left|c^{*}\right| d S_{n-1}\right) d t+2 M_{1} \int_{t_{n-1}}^{t_{n}}\left(\iiint_{G_{n-1}}|F| d G_{n-1}\right) d t \\
& \iiint_{G_{n-1}}\left(c^{(n)}\right)^{2} d G_{n-1} \leq M_{6, n-1}\left(\iiint_{G_{n-1}} c_{0}^{2} d G_{n-1}+\right. \\
& \left.+M_{4, n-1} \int_{t_{n-1}}^{t_{n}}\left(\iint_{S_{c, n-1}}\left(c^{*}\right)^{2} d S_{n-1}\right) d t+2 M_{2, n-1} M_{3, n-1} \int_{t_{n-1}}^{t_{n}}\left(\iint_{S_{c, n-1}}\left|c^{*}\right| d S_{n-1}\right) d t+2 M_{1, n-1} \int_{t_{n-1}}^{t_{n}}\left(\iint_{G_{n-1}} \int|F| d G_{n-1}\right) d t\right) \\
& \left.M_{1, n-1} \equiv \max _{\Omega}\left\{\mid c^{(n)}\right\}\right\}, \\
& M_{2, n-1} \equiv \max _{S_{n-1}}\left\{\left|\frac{\partial c^{(n)}}{\partial x}\right|\left|\frac{\partial c^{(n)}}{\partial y}\right|\right\}, \\
& M_{3, n-1} \equiv \max _{S_{c, n-1}}\left\{\mu_{h}\right\}, \\
& M_{4, n-1} \equiv \max _{S_{c, n-1} \times t_{n-1} \leq t \leq t_{n} n}\{|u|,|v|\}
\end{aligned}
$$




$$
\begin{gathered}
M_{5, n-1} \equiv \min _{G_{n-1}}\left\{\mu_{h}, \mu_{v}\right\}, \\
M_{6, n-1}=\frac{1}{2 M_{5, n-1}}\left(\pi^{2}\left(\frac{1}{L_{x}^{2}}+\frac{1}{L_{y}^{2}}+\frac{1}{\left(H^{(n-1)}\right)^{2}}\right)\right)^{-1} .
\end{gathered}
$$

Conclusion. The authors proposed a mathematical continuous spatial-three-dimensional model of transport and sedimentation of suspended matter, taking into account changes in the bottom topography. The study of this model is carried out by its linearization. The conditions for the existence and uniqueness of the linearized initial-boundary value problem are determined. In addition, an a priori estimate is obtained depending on the integral estimates of the right-hand side, boundary conditions, and the initial condition.

The results of the study of the model of transport and sedimentation of suspensions can be used in predicting hydrodynamic processes, increasing their accuracy and reliability due to the presence of new functionalities of taking into account physically important factors, including clarifying the boundary conditions.

\section{References}

1. Sukhinov, A.I., Sidoryakina, V.V., Sukhinov, A.A.: Sufficient convergence conditions for positive solutions of linearized two-dimensional sediment transport problem. J. Computational Mathematics and Information Technologies. 1, (1). pp. 21-35. (2017). doi: 10.23947/2587-89992017-1-1-21-35

2. Nikitina A.V., Semenyakina A.A. Mathematical modeling of eutrophication processes in Azov Sea on supercomputers // Computational Mathematics and Information Technologies. 2017. V.1, No 1. - pp. 82-101.

3. Sukhinov A.I., Chistyakov A.E., Sidoryakina V.V. (2018) Parallel Solution of Sediment and Suspension Transportation Problems on the Basis of Explicit Schemes. In: Sokolinsky L., Zymbler M. (eds) Parallel Computational Technologies. PCT 2018. Communications in Computer and Information Science, V. 910. Springer, Cham DOI: https://doi.org/10.1007/978-3-319-996738_22.

4. Barnard, P.L. A multi-discipline approach for understanding sediment transport and geomorphic evolution in an estuarine-coastal system - San Francisco Bay / P.L. Barnard, B.E. Jaffe, and D.H. Schoellhamer // Marine Geology. Marine Geology. - 2013. Vol. 345. pp. 1-2. DOI:10.1016/j.margeo.2013.09.010.

5. A. Sukhinov, A. Chistyakov, V. Sidoryakina Investigation of nonlinear 2D bottom transportation dynamics in coastal zone on optimal curvilinear boundary adaptive grids // MATEC Web of Conferences Volume 132 (2017) XIII International Scientific-Technical Conference "Dynamic of Technical Systems" (DTS-2017), Rostov-on-Don, Russian Federation, September 1315, 2017. DOI: https://doi.org/10.1051/matecconf/201713204003

6. Lusher, A.L. Occurrence of microplastics in gastrointestinal tract of pelagic and demersal fish from the English channel / A.L. Lusher, M. McHugh, R.C. Thompson // Marine Pollution Bulletin. - 2013. - Vol. 67. - pp. 94-99. 
7. G. I. Marchuk, V. P. Dymnikov, and V. B. Zalesny. Mathematical Models in Geophysical Hydrodynamics and Numerical Methods for Their Implementation. Leningrad: Geophysical, 1987. - 296 p.

8. Alekseenko, E., Roux, B., Sukhinov, A., Kotarba, R., Fougere, D. Coastal Hydrodynamics in a Windy Lagoon. J. Computers and Fluids. 77, pp. 24-35 (2013). doi: 10.1016/j.compuid.2013.02.003.

9. Sanne, L.N. Modelling of sand dunes in steady and tidal flow / L.N Sanne // Denmark: Technical University of Copenhagen. - 2003. - 185 p.

10. Ballent, A. Modelled transport of benthic marine microplastic pollution in the Nazaré Canyon / A. Ballent, S. Pando, A. Purser, M. Juliano, L. Thomsen// Biogeosciences. - 2013. - Vol. 10. - pp. 7957-7970. https://doi.org/10.5194/bg-10-7957-2013, 2013.

11. Miles, J. Wave shape effects on sediment transport / J. Miles, J. // J. Coastal Res. 2013. - Vol. 2, iss. 65. - pp. 1803-1808. DOI::10.2112/SI65-305.1

12. Sukhinov A., Sidoryakina V., Protsenko S. Correctness investigation for the suspension transport problem in coastal systems. MATEC Web Conf. Volume 226, 04027 (2018) XIV International Scientific-Technical Conference "Dynamic of Technical Systems" (DTS-2018) 2018. DOI: https://doi.org/10.1051/matecconf/201822604027

13. Matishov G.G., Polshinin V.V., Dyuzhova K.V., Sushko KS, Titov V.V. The results of comprehensive studies of the Holocene deposits of the Taganrog Bay of the Azov Sea // Science of the South of Russia. 2017 T. 13 № 4 pp. 43-59.

14. Sidoryakina, V.V., Sukhinov, A.I.: Well-posedness analysis and numerical implementation of a linearized two-dimensional bottom sediment transport problem. J. Comput. Math. Math. Phys. 57(6), pp. 978-994 (2017). https://doi.org/10.1134/s0965542517060124

15. Sukhinov A.I., Sidoryakina V.V. On the convergence of solutions of linearized on a time grid sequence problem to the solution of nonlinear problems of sediment transport // Mathematical Models and Computer Simulations, 2017. - V. 29, Issue 11. - pp. 19-39.

16. Sukhinov A.I., Sidoryakina V.V., Sukhinov A.A. Sufficient conditions for convergence of positive solutions to linearized two-dimensional sediment transport problem. Vestnik of Don State Technical University. 2017; 17(1): pp. 5-17. (In Russ.) https://doi.org/10.23947/19925980-2017-17-1-5-17

17. Sukhinov, A.A. 3D Model of Diffusion-Advection-Aggregation Suspensions in Water Basins and Its Parallel Realization / A.A. Sukhinov, A.I. Sukhinov // Parallel Computational Fluid Dynamics, Mutidisciplinary Applications, Proceedings of Parallel CFD 2004 Conference, Las Palmas de Gran Canaria, Spain, ELSEVIER, Amsterdam-Berlin-London-New York-Tokyo. - 2005. - pp. 223-230. DOI: 10.1016/B978-044452024-1/50029-4.

18. Protter, M.H. Maximum Principles in Differential Equation / M.H. Protter, H.F. Weinberger // Springer-Verlag New York, Inc. - 1984. - 276 p. DOI 10.1007/978-1-4612-5282-5.

19. Ladyzhenskaya O.A., Solonnikov V.A. and Ural'tseva N.N. Linear and Quasilinear Equations of Parabolic Type. Nauka, Moscow, 1967.- 736 p.

20. Vladimirov V.S. Equations of mathematical physics. Textbook. 4th edition, revised and enlarged. - Moscow: Science, 1981.- 512 p.

21. Tikhonov A.N., Samarskiy A.A. Equations of Mathematical Physics. - Moscow: Science, 1977. $-735 \mathrm{p}$. 


\section{Authors:}

Sukhinov Alexander Ivanovich, Don State Technical University (1st Gagarin Square, Rostov-onDon, Russian Federation), Doctor of Science in Physics and Maths, Professor

Sidoryakina Valentina Vladimirovna, Taganrog Institute of A.P. Chekhov (branch) RSUE (Initiative Street, Taganrog, Russian Federation), Candidate of Science in Physics and Maths, Associate professor 


\section{Построение и исследование корректности математической модели транспорта и осаждения взвесей с учетом изменений рельефа дна *}

\section{А.И. Сухинов ${ }^{* *}$, В.В. Сидорякина ${ }^{* * *}$}

Донской государственный технический университет, Ростов-на-Дону, Российская Федерация Таганрогский институт им. А.П. Чехова (филиал) РГЭУ (РИНЭ), Таганрог, Россия

Настоящая работа посвящена исследованию пространственно-трехмерной модели транспорта и осаждения взвеси в прибрежной зоне с учетом изменения рельефа дна. Модель учитывает следующие процессы: адвективный перенос, обусловленный движением водной среды, микротурбулентную диффузию и гравитационное осаждение частиц взвеси, а также изменение геометрии дна, вызванное осаждением частиц взвеси или подъемом частиц донных отложений. Изменение рельефа дна приводит к необходимости решать начально-краевую задачу для уравнения параболического типа с младшими производными в области, геометрия которой зависит от искомой функции решения, что приводит, в общем случае, к нелинейной постановке задачи.

Выполнена линеаризация модели на временной сетке за счет «замораживания» рельефа дна в пределах одного шага по времени и последующего пересчета функции поверхности дна на основе изменившейся функции концентрации взвешенного вещества, а также возможного изменения вектора скорости движения водной среды. Получена априорная оценка нормы решения в функциональном пространстве $\mathrm{L}_{2}$ в зависимости от интегральных оценок по времени правой части, граничных условий и начального условия, и, таким образом, доказана устойчивость решения исходной задачи от изменения начального и граничных условий и функции правой части. Модель может представлять ценность при прогнозе распространения загрязнений и изменения рельефа дна, как при антропогенном воздействии, так и в силу естественно протекающих природных процессов в прибрежной зоне.

Ключевые слова: прибрежные системы, математическая модель, диффузионноконвективные задачи осаждения взвеси, изменение рельефа дна, единственность решения и устойчивость начально-краевой задачи

\footnotetext{
* Работа выполнена по теме № 2.6905.2017/БЧ в рамках выполнения госзадания Минобрнауки России в части НИР.

** E-mail: sukhinov@gmail.com.

***E-mail: cvv9@mail.ru.
} 


\section{Авторы:}

Сухинов Александр Иванович, Донской государственный технический университет (344000 Ростов-на-Дону, пл. Гагарина, д. 1), доктор физико-математических наук, профессор

Сидорякина Валентина Владимировна, Таганрогский институт им. А.П. Чехова (филиал) РГЭУ (РИНЭ) (347936 Таганрог, улица Инициативная, д. 48), кандидат физикоматематических наук, доцент 